Tropical Journal of Pharmaceutical Research October 2020; 19 (10): 2205-2212

ISSN: $1596-5996$ (print); 1596-9827 (electronic) (C) Pharmacotherapy Group, Faculty of Pharmacy, University of Benin, Benin City, 300001 Nigeria.

\title{
Periodontal status among adult cigarette smokers using Miswak (Salvadora persica) for oral hygiene: A cross- sectional study from Asir Region of Saudi Arabia
}

\author{
Mukhatar A Javali*, Betsy Joseph, Nabeeh A AlQahtani, Mohasin Abdul \\ Khader, Shahabe Saquib Abullias, Saad M AIQahtani \\ Department of Periodontics and Community Dental Sciences, Division of Periodontics, College of Dentistry, King Khalid \\ University, Abha, Kingdom of Saudi Arabia \\ *For correspondence: Email: jmahmad@kku.edu.sa; Tel: 00966580540089
}

Sent for review: 15 June 2020

Revised accepted: 21 September 2020

\begin{abstract}
Purpose: To compare the periodontal status of exclusive users of Miswak (Salvadora persica) with that of exclusive toothbrush users among adult smokers of cigarettes in Saudi Arabia.

Methods: This educational-institutional study included one hundred and fifty adult patients (age and socioeconomic status matched, SES) between the ages of 18 and 75, and were listed as the group I, II, and III, with 50 participants each (participants with no oral hygiene, toothbrush users and miswak users respectively). Oral hygiene habits, the number of cigarettes smoked, and time since the habit began. Periodontal and radiographic parameters were reported.

Results: All parameters related to periodontium (plaque index (PI), gingival index (GI), bleeding on probing $(B O P)$, probing pocket depth (PPD), gingival recession (Rec), clinical attachment level (CAL) and bone loss $(B L))$ showed that the analysed groups exhibited differences $(p<0.001)$. Least amount of $B L$ (anterior and posterior) was found in toothbrush users and Miswak users, while least amount of attachment loss (both anterior and posterior) was recorded among Miswak users ( $p>0.05)$. Positive association was found for $G I(r=0.753)$ and recession $(r=0.436, p<0.001)$ in terms of the number of cigarettes smoked in group I, and anterior PPD $(r=0.388, p<0.001)$ in group III for the duration of smoking. A negative correlation was found for BOP in group III $(r=-0.339, p<0.05)$ in terms of frequency of tooth cleaning and $\mathrm{GI}(r=-0.381)(p<0.001)$ in group II, in terms of time taken attain oral hygiene.

Conclusion: This study indicates less severe periodontal damage among adult current cigarette smokers in miswak users than in toothbrush users. Thus, there some potentials for miswak use for promotion of oral hygiene.
\end{abstract}

Keywords: Periodontal status, Adult cigarette smokers, Miswak, Oral hygiene

This is an Open Access article that uses a fund-ing model which does not charge readers or their institutions for access and distributed under the terms of the Creative Commons Attribution License (http://creativecommons.org/licenses/by/4.0) and the Budapest Open Access Initiative (http://www.budapestopenaccessinitiative.org/read), which permit unrestricted use, distribution, and reproduction in any medium, provided the original work is properly credited.

Tropical Journal of Pharmaceutical Research is indexed by Science Citation Index (SciSearch), Scopus, International Pharmaceutical Abstract, Chemical Abstracts, Embase, Index Copernicus, EBSCO, African Index Medicus, JournalSeek, Journal Citation Reports/Science Edition, Directory of Open Access Journals (DOAJ), African Journal Online, Bioline International, Open-J-Gate and Pharmacy Abstracts

\section{INTRODUCTION}

The use of cigarettes is regarded as a primary risk factor for periodontal disease causation [1].
Evidence of strong association between tobacco use and progressive periodontal damage is present in the literature [1]. Studies record significantly higher pocket depth scores in 
smokers and alveolar bone loss than in nonsmokers [2]. Oral hygiene aids have an essential part to play in avoiding periodontal disease. Among these, aside from antiplaque effects, herbal oral hygiene tools were anti-inflammatory and anticariogenic. Different sections of Miswak (drawn from a plant species of Salvadora persica belonging to the Salvadoraceae family) such as twigs, stem, and roots were used to extract plaque from the oral cavity [3], including interdental areas [4]. Miswak (S. persica) has a broad geographical range, and its beneficial properties are considered to be exercised by the fibres' abrasive effects and by the presence of therapeutic chemicals. It has been found that repeated Miswak chewing releases its sap, which can may have protective effects against caries [5]. Due to the essential oils, the slightly bitter taste of miswak acts as a buffering agent and activates salivation. It has been found high chloride concentrations inhibit calculus from forming and help remove stains from tooth surfaces [6]. The use of chewing sticks enhanced calcium saturation in saliva and facilitated enamel remineralization [7]. Miswak's roots are also considered to include chlorides, flavonoids, fluorides, tannins, saponins and sterols, sulphur and ascorbic acid [6].

It has been found that the use of miswak has a protective effect on the periodontium, caries, and low need for periodontal care [8] However, contradictory findings exist where miswak users have deeper periodontal pockets or just marginal better periodontal status than non-users [9]. Since there are insufficient data on periodontal status and bone loss in smokers who are miswak users, this study was done with the primary objective of determining whether there exists any difference in periodontal parameters selected for the study. Furthermore, the purpose of this study was also to determine the nature of the association between the number of cigarettes smoked and the duration of smoking or frequency with that of above listed clinical parameters.

\section{METHODS}

\section{Study design}

This educational institution-based cross-sectional study was performed between March 2019 and May 2019 in the outpatient department of King Khalid University, College of Dentistry. The Institutional Review Board at the College of Dentistry approved the study (no. SRC/ETH/2018-19/108). The research was performed in full accordance with the ethical standards of the Helsinki Declaration of the
World Medical Association (version 2008). The participants had given informed consent before their enrolment in the study.

Consenting participants who were current cigarette smokers with periodontitis (according to AAP 2018) [10] using either toothbrush with a non-herbal fluoridated toothpaste or fresh miswak stick (twig) for oral hygiene maintenance were recruited for the study.One hundred fifty adult patients between 18 and 75 years were listed as group I ( $\mathrm{n}=50$; no oral hygiene), group II ( $n=50$; toothbrush users) or group III ( $n=50$; Miswak users). Based on the mean $\pm \mathrm{SD}$ of $\mathrm{CAL}$ in three groups of our pilot study, the effect size was determined to be 0.35 (taking likelihood alpha error 0.05 and 95 percent research power), and thus the sample size was estimated to be 129 i.e. 43 in each group. Therefore, the study included 150 patients (age and socioeconomic (SES) matched) from an existing list, taking into account 10 percent margin of error in each group). The exclusion criteria were those cases where cementoenamel junction (CEJ) or the bone crest was not identified adequately (overlapping, caries or restorations), presence of any systemic condition, family history of periodontal disease, periodontal therapy in the last six months, and systemic antibiotics within the last three months. Patients were given the definitive treatment following the registration of all relevant parameters.

\section{Periodontal examination}

Probing pocket depth, gingival recession, and interdental $\mathrm{CAL}$ was recorded at the most significant loss using the University of Michigan O probe with William's markings. Periodontal destruction was reported separately in the anterior and posterior segments in PPD, GR and $\mathrm{CAL}$ [11]. A patient was considered to have periodontitis if interdental CAL was detectable in two or more non-adjacent teeth, or if buccal or oral CAL of $3 \mathrm{~mm}$ or more with pocketing of $3 \mathrm{~mm}$ or more was detectable at two or more teeth. This was following the new classification of periodontal disease (2018) [10]. However, CAL was not considered due to non-periodontitisrelated causes such as dental caries spreading through the cervical region of the tooth; the presence of CAL distal to molars or associated with malposition or extraction of a third molar; an endodontic lesion draining through the marginal periodontium; and the occurrence of a vertical root fracture. Gingival inflammation and oral hygiene status were also assessed using $\mathrm{Gl}$ and $\mathrm{PI}$, while BOP was recorded using gingival bleeding index.

\section{Radiographic examination}


The amount of BL in each patient's worst affected tooth was recorded from crest of alveolar bone to cementoenamel junction (CEJ). $\mathrm{BL}$ was recorded separately in the anterior and posterior regions since nicotine exerts more destructive actions in the anterior region due to its vasoconstrictive effects [11]. The radiographic method used was similar technique (Kodak Ultra speed Dental Film, Eastman Kodak, Rochester, NY, USA) with a Siemens Heliodent MD model X1744 (Sirona Dental Systems, GmbH D-64625, Bensheim, Germany) in order to standardize. The X-ray machine used was a $70 \mathrm{kV}$ and seven $\mathrm{mA}$ machine. Before the recording of clinical and radiographic parameters for the study, the two examiners evaluated these in five patients twice, 48 hours apart, to calibrate the readings. In case 90 percent or more of the recordings could reproduce within a $1-\mathrm{mm}$ difference, then the calibration was accepted.

\section{Statistical analysis}

The data are expressed as mean \pm SD (quantitative data) and numbers and percentages (qualitative data). Since the data was normally distributed, parameters such as oral hygiene practices (qualitative) and periodontal and radiographic parameters (quantitative) between different study groups were tested using Chisquare test and analysis of variance (ANOVA) along with post-hoc respectively at $95 \%$ Confidence interval $(\mathrm{Cl})$. Correlation between various parameters was done using Pearson's analysis, and the results were expressed in terms of $p$-value and Pearson's Coefficient ( $r$ ). Statistical analysis was done using SPSS 17.0 version.

\section{RESULTS}

One hundred and fifty patients (with a positive history of smoking) were found eligible to participate in the study following the inclusion and exclusion requirements. In each group, there were 50 patients (group I: no oral hygiene method used, 50 in group II (users of toothbrush), and 50 in group III (users of the miswak). Descriptive statistics for the demographic data between the various sample groups shown in Table 1 indicate no differences in age and SES ( $p>0.05)$.

There was no statistically significant difference in terms of frequency of teeth brushing, the time taken for teeth brushing, the number of cigarettes smoked, and duration of smoking (Table 2). Although the highest number of cigarettes used every day was among patients of group III (11.52 \pm 6.37 and the lowest in group II $(9.90 \pm 2.57)$, this difference was statistically insignificant $(p=$ $0.321)$. The majority of group II and III subjects brushed their teeth once a day (48\% and $38 \%$ respectively). Group II reported the most prolonged time of smoking cigarettes while it was shortest for group III, and this too showed no statistically significant difference $(p=0.248)$.

Table 1: Descriptive analysis of demographic variables amongst the different study groups

\begin{tabular}{|c|c|c|c|c|c|c|c|c|}
\hline \multirow[t]{2}{*}{ Variable } & \multirow[t]{2}{*}{ Response } & \multicolumn{2}{|c|}{ Group I $(n=50)$} & \multicolumn{2}{|c|}{ Group II $(n=50)$} & \multicolumn{2}{|c|}{ Group III $(n=50)$} & \multirow[t]{2}{*}{$P$-value } \\
\hline & & $\mathrm{n}$ & $\%$ & $\mathrm{n}$ & $\%$ & $\mathrm{n}$ & $\%$ & \\
\hline Age & Mean \pm SD & \multicolumn{2}{|c|}{$34.08 \pm 6.51$} & \multicolumn{2}{|c|}{$34.98 \pm 8.98$} & \multicolumn{2}{|c|}{$36.84 \pm 6.51$} & $0.169^{\text {ns }}$ \\
\hline \multirow[t]{3}{*}{ SES } & Lower & 12 & 24 & 14 & 28 & 9 & 18 & $0.826^{\mathrm{ns}}$ \\
\hline & Middle & 28 & 56 & 26 & 52 & 29 & 58 & \\
\hline & Upper & 10 & 20 & 10 & 20 & 12 & 24 & \\
\hline
\end{tabular}

Table 2: Comparative analysis of variables related to oral hygiene practices and smoking habits of subjects in each study group

\begin{tabular}{|c|c|c|c|c|c|c|c|c|}
\hline \multirow[t]{2}{*}{ Variable } & \multirow[t]{2}{*}{ Response } & \multicolumn{2}{|c|}{$\begin{array}{c}\text { Group I } \\
(n=50)\end{array}$} & \multicolumn{2}{|c|}{$\begin{array}{c}\text { Group II } \\
(n=50)\end{array}$} & \multicolumn{2}{|c|}{$\begin{array}{c}\text { Group III } \\
(n=50)\end{array}$} & \multirow[t]{2}{*}{$P$-value } \\
\hline & & $\mathrm{n}$ & $\%$ & $\mathrm{n}$ & $\%$ & $\mathrm{~N}$ & $\%$ & \\
\hline \multirow[t]{3}{*}{ Frequency } & 1 & 0 & 0 & 24 & 48 & 19 & 38 & \multirow[t]{3}{*}{$0.454^{\mathrm{ns}}$} \\
\hline & 2 & 0 & 0 & 10 & 20 & 15 & 30 & \\
\hline & 3 & 0 & 0 & 16 & 32 & 16 & 32 & \\
\hline \multirow[t]{3}{*}{ Time taken } & 1 & 0 & 0 & 28 & 56 & 25 & 50 & \multirow[t]{3}{*}{$0.767^{\text {ns }}$} \\
\hline & 2 & 0 & 0 & 17 & 34 & 18 & 36 & \\
\hline & 3 & 0 & 0 & 5 & 10 & 7 & 14 & \\
\hline No. of cigarettes & Mean \pm SD & \multicolumn{2}{|c|}{$10.70 \pm 6.23$} & \multicolumn{2}{|c|}{$9.90+257$} & \multicolumn{2}{|c|}{$11.52+6.37$} & $0.321^{\mathrm{ns}}$ \\
\hline Duration & Mean \pm SD & \multicolumn{2}{|c|}{$14.70 \pm 8.57$} & \multicolumn{2}{|c|}{$15.96 \pm 8.44$} & \multicolumn{2}{|c|}{$13.06 \pm 8.98$} & $0.248^{\text {ns }}$ \\
\hline
\end{tabular}

ns: not significant; ${ }^{*} p<0.05$ : significant; ${ }^{* *} p<0.001$ : highly significant; SD: standard deviation 
All the periodontal parameters ( $\mathrm{PI}, \mathrm{GI}, \mathrm{BOP}$, PPD, GR, CAL and BL)) showed a statistically significant difference between the study groups $(p<0.001)$, as shown in Table 3. From the group I to III, PI and GI were down. The lowest amount of $\mathrm{BL}$ (anterior and posterior) was observed in users of toothbrush and miswak, respectively ( $p$ $>0.05$ ). The lowest CAL (both anterior and posterior) was recorded among miswak users ( $p$ $>0.05)$. Table 4 show the details of post hoc Bonferroni test results for comparing the periodontal variables between study groups. Subsequently, Pearson correlation (95\% Cl) analysis was done between periodontal variables with the smoking habit (number of cigarettes and smoking) as shown in Table 5 and Table 6. It showed a positive correlation of $\mathrm{Gl}(r=0.753)$ and recession $(r=0.436)(p<0.001)$ for the number of cigarettes smoked in group $\mathrm{I}$, and anterior PPD $(r=0.388)(p<0.001)$ for the duration of smoking (in years) in group III. There is also a negative correlation of BOP in group III or $(r=-0.339)(p<0.05)$ for the frequency of tooth cleaning and $\mathrm{GI}(r=-0.381)(p<0.001)$ in group II.

\section{DISCUSSION}

Smoking tobacco is a notable risk factor that causes and advancement of periodontal disease. It is also listed as the second major risk factor for global death and disability and is a significant health in Saudi Arabia [1]. Smoking prevalence varies from 2 to 52 percent across different strata of the Saudi Arabia population [11]. Diverse factors responsible for smoking adverse effects include enhanced oxidative stress, diminished antioxidant defenses, elevated inflammatory activity, and compromised tissue repair capacities [1]. It has been commonly observed that smokers have a substantially higher plaque index than non- smokers, an average amount of bleeding on probing [12]. However, as far as we know, this is the first study that disclose the periodontal status in smokers among miswak users as an oral hygiene method.

Table 3: Comparative analysis of periodontal variables between study groups

\begin{tabular}{lcccc}
\hline Variable & Group I $(\mathbf{n}=\mathbf{5 0})$ & Group II $(\mathbf{n}=\mathbf{5 0})$ & Group III $(\mathbf{n}=\mathbf{5 0})$ & P-value \\
\cline { 2 - 4 } & Mean \pm SD & Mean \pm SD & Mean \pm SD & \\
PI & $2.29 \pm 0.41$ & $1.64 \pm 0.52$ & $1.38 \pm 0.37$ & $0.000^{*}$ \\
GI & $2.22 \pm 0.31$ & $1.78 \pm 0.53$ & $1.57 \pm 0.44$ & $0.000^{*}$ \\
BOP & $90.00 \pm 15.15$ & $85.00 \pm 17.49$ & $79.50 \pm 27.05$ & $0.041^{*}$ \\
PPD Anterior & $3.80 \pm 1.28$ & $3.01 \pm 0.64$ & $2.87 \pm 0.75$ & $0.000^{*}$ \\
Rec Anterior & $3.20 \pm 0.67$ & $2.50 \pm 0.97$ & $2.34 \pm 1.19$ & $0.000^{*}$ \\
CAL Anterior & $6.21 \pm 0.51$ & $6.14 \pm 2.03$ & $5.37 \pm 1.28$ & $0.006^{*}$ \\
PPD Posterior & $4.03 \pm 1.18$ & $3.13 \pm 0.72$ & $3.28 \pm 0.55$ & $0.000^{*}$ \\
Rec Posterior & $3.18 \pm 0.63$ & $2.44 \pm 0.90$ & $2.34 \pm 1.19$ & $0.000^{*}$ \\
CAL Posterior & $6.46 \pm 0.62$ & $6.37 \pm 1.84$ & $5.57 \pm 1.22$ & $0.001^{*}$ \\
BL Anterior & $2.56 \pm 0.58$ & $2.16 \pm 1.67$ & $1.92 \pm 1.14$ & $0.030^{*}$ \\
BL Posterior & $3.59 \pm 2.13$ & $2.89 \pm 1.66$ & $2.55 \pm 1.68$ & $0.018^{*}$ \\
\hline
\end{tabular}

$\mathrm{PI}$ : plaque index; GI: gingival index; BOP: bleeding on probing; PPD: probing pocket depth; Rec: recession; CAL: clinical attachment level; BL: bone loss; ns: not significant; ${ }^{*} p<0.05$; significant; ${ }^{* *} p<0.001$; highly significant; SD: standard deviation

Table 4: Post hoc Bonferroni test results for comparative analysis of different periodontal variables between study groups

\begin{tabular}{lcccccc}
\hline Variable & \multicolumn{2}{c}{ Group I vs II } & \multicolumn{2}{c}{ Group I vs III } & \multicolumn{2}{c}{ Group II vs III } \\
\cline { 2 - 6 } & $\begin{array}{c}\text { Mean } \\
\text { difference }\end{array}$ & P-value & $\begin{array}{c}\text { Mean } \\
\text { difference }\end{array}$ & P-value & $\begin{array}{c}\text { Mean } \\
\text { difference }\end{array}$ & P-value \\
\hline PI & 0.655 & $0.000^{*}$ & 0.917 & $0.000^{*}$ & 0.262 & $0.010^{*}$ \\
GI & 0.439 & $0.000^{*}$ & 0.651 & $0.000^{*}$ & 0.211 & $0.052^{\mathrm{ns}}$ \\
BOP & 5.000 & $0.678^{\text {ns }}$ & 10.500 & $0.035^{*}$ & 5.500 & $0.549^{\mathrm{ns}}$ \\
PPD anterior & 0.795 & $0.000^{*}$ & 0.930 & $0.000^{*}$ & 0.135 & $1.00^{\mathrm{ns}}$ \\
Rec anterior & 0.700 & $0.001^{*}$ & 0.860 & $0.000^{*}$ & 0.160 & $1.00^{\mathrm{ns}}$ \\
CAL anterior & 0.065 & $1.00^{\mathrm{ns}}$ & 0.835 & $0.011^{*}$ & 0.770 & $0.022^{*}$ \\
PPD posterior & 0.901 & $0.000^{*}$ & 0.751 & $0.000^{*}$ & 0.150 & $1.00^{\mathrm{ns}}$ \\
Rec posterior & 0.740 & $0.000^{*}$ & 0.840 & $0.000^{*}$ & 0.100 & $1.00^{\mathrm{ns}}$ \\
CAL posterior & 0.088 & $1.00^{\mathrm{ns}}$ & 0.890 & $0.003^{*}$ & 0.801 & $0.009^{*}$ \\
BL anterior & 0.403 & $0.298^{\mathrm{ns}}$ & 0.646 & $0.026^{*}$ & 0.243 & $0.956^{\mathrm{ns}}$ \\
BL posterior & 0.696 & $0.180^{\mathrm{ns}}$ & 1.037 & $0.016^{*}$ & 0.341 & $1.00^{\mathrm{ns}}$ \\
\hline Pl: plaque index; Gl: gingival index; BOP: bleeding on probing; PPD: probing pocket depth; Rec: recession; CAL.
\end{tabular}

PI: plaque index; GI: gingival index; BOP: bleeding on probing; PPD: probing pocket depth; Rec: recession; CAL: clinical attachment level; BL: bone loss; ns: not significant; ${ }^{*} p<0.05$; significant; ${ }^{* *} p<0.001$; highly significant; SD: standard deviation 
Table 5: Correlational analysis of periodontal variables with smoking habit

\begin{tabular}{|c|c|c|c|c|c|c|c|}
\hline \multirow[t]{2}{*}{ Parameter } & \multirow[t]{2}{*}{ Variable } & \multicolumn{2}{|c|}{ Group I } & \multicolumn{2}{|c|}{ Group II } & \multicolumn{2}{|c|}{ Group III } \\
\hline & & $r$ & $P$-value & $r$ & $P$-value & $r$ & $P$-value \\
\hline \multirow{11}{*}{$\begin{array}{l}\text { No. of } \\
\text { cigarettes } \\
\text { smoked }\end{array}$} & Plaque Index & 0.219 & $0.126^{\mathrm{ns}}$ & -0.084 & $0.563^{\mathrm{ns}}$ & 0.074 & $0.612^{\mathrm{ns}}$ \\
\hline & Gingival Index & 0.753 & $0.000^{* *}$ & -0.101 & $0.483^{n s}$ & 0.092 & $0.525^{\mathrm{ns}}$ \\
\hline & BOP & 0.346 & $0.014^{*}$ & 0.023 & $0.876^{n s}$ & 0.019 & $0.897^{\mathrm{ns}}$ \\
\hline & PPD Anterior & 0.107 & $0.458^{n s}$ & -0.076 & $0.599 \mathrm{~ns}$ & 0.191 & $0.185^{\mathrm{ns}}$ \\
\hline & Rec Anterior & 0.357 & $0.011^{*}$ & -0.102 & $0.482^{n s}$ & 0.178 & $0.215^{\mathrm{ns}}$ \\
\hline & CAL Anterior & -0.165 & $0.252^{\mathrm{ns}}$ & 0.256 & $0.073^{n s}$ & 0.271 & $0.057^{\mathrm{ns}}$ \\
\hline & PPD Posterior & 0.059 & $0.682^{n s}$ & -0.405 & $0.004^{* *}$ & -0.025 & $0.864^{\mathrm{ns}}$ \\
\hline & Rec Posterior & 0.436 & $0.002^{\star *}$ & 0.019 & $0.895^{n s}$ & 0.178 & $0.215^{\mathrm{ns}}$ \\
\hline & CAL Posterior & 0.338 & $0.016^{*}$ & 0.035 & $0.81^{\mathrm{ns}}$ & 0.184 & $0.201^{\mathrm{ns}}$ \\
\hline & BL Anterior & -0.287 & $0.044^{*}$ & 0.043 & $0.767^{n s}$ & -0.082 & $0.573^{n s}$ \\
\hline & BL Posterior & -0.204 & $0.154^{\mathrm{ns}}$ & 0.132 & $0.36^{\mathrm{ns}}$ & -0.029 & $0.84^{\text {ns }}$ \\
\hline \multirow{11}{*}{$\begin{array}{l}\text { Duration of } \\
\text { smoking } \\
\text { (number of } \\
\text { years) }\end{array}$} & Plaque Index & 0.161 & $0.263^{n s}$ & 0.216 & $0.131^{\mathrm{ns}}$ & 0.266 & $0.062^{\mathrm{ns}}$ \\
\hline & Gingival Index & 0.022 & 0.879 ns & 0.218 & $0.128^{n s}$ & 0.119 & $0.41^{\mathrm{ns}}$ \\
\hline & BOP & 0.134 & $0.355^{\mathrm{ns}}$ & 0.082 & $0.57^{\mathrm{ns}}$ & -0.171 & $0.234^{n s}$ \\
\hline & PPD Anterior & 0.087 & $0.546^{\mathrm{ns}}$ & 0.111 & $0.443^{n s}$ & 0.388 & $0.005^{\star *}$ \\
\hline & Rec Anterior & 0.142 & $0.325^{\mathrm{ns}}$ & -0.04 & $0.784^{n s}$ & 0.052 & $0.722^{n s}$ \\
\hline & CAL Anterior & 0.042 & $0.772^{\mathrm{ns}}$ & 0.356 & $0.011^{*}$ & 0.328 & $0.02^{*}$ \\
\hline & PPD Posterior & -0.092 & $0.526 \mathrm{~ns}$ & -0.024 & $0.867^{n s}$ & -0.162 & $0.261^{\mathrm{ns}}$ \\
\hline & Rec Posterior & 0.097 & $0.501 \mathrm{~ns}$ & -0.035 & $0.81^{\mathrm{ns}}$ & 0.052 & $0.722^{n s}$ \\
\hline & CAL Posterior & 0.252 & $0.077^{n s}$ & 0.262 & $0.066^{\mathrm{ns}}$ & 0.280 & $0.049^{*}$ \\
\hline & B L Anterior & -0.297 & $0.036^{*}$ & 0.356 & $0.011^{*}$ & 0.062 & $0.667^{\mathrm{ns}}$ \\
\hline & BL Posterior & -0.327 & $0.02^{*}$ & 0.307 & $0.03^{*}$ & 0.224 & $0.117^{\mathrm{ns}}$ \\
\hline
\end{tabular}

PI: plaque index; GI: gingival index; BOP: bleeding on probing; PPD: probing pocket depth; Rec: recession; CAL: clinical attachment level; BL: bone loss; ns: not significant; ${ }^{*} p<0.05$; significant; ${ }^{* *} p<0.001$; highly significant; SD: standard deviation

Table 6: Correlation Analysis of periodontal variables with tooth cleansing habit

\begin{tabular}{|c|c|c|c|c|c|c|c|}
\hline \multirow[t]{2}{*}{ Parameter } & \multirow[t]{2}{*}{ Variable } & \multicolumn{2}{|c|}{ Group I } & \multicolumn{2}{|c|}{ Group II } & \multicolumn{2}{|c|}{ Group III } \\
\hline & & r value & $P$-value & r value & $P$-value & r value & $P$-value \\
\hline \multirow[t]{11}{*}{ Frequency } & $\mathrm{PI}$ & - & - & -0.015 & $0.916^{\mathrm{ns}}$ & 0.099 & $0.493^{\mathrm{ns}}$ \\
\hline & $\mathrm{GI}$ & - & - & -0.07 & $0.629^{n s}$ & 0.099 & $0.494^{\text {ns }}$ \\
\hline & BOP & - & - & 0.115 & $0.425^{\mathrm{ns}}$ & -0.339 & $0.016^{*}$ \\
\hline & PPD Anterior & - & - & 0.242 & $0.09^{n s}$ & -0.037 & $0.8^{\mathrm{ns}}$ \\
\hline & Rec Anterior & - & - & -0.141 & $0.33^{\mathrm{ns}}$ & 0.037 & $0.797^{\mathrm{ns}}$ \\
\hline & CAL Anterior & - & - & 0.107 & $0.459^{n s}$ & 0.005 & $0.973^{n s}$ \\
\hline & PPD Posterior & - & - & 0.049 & $0.736^{\mathrm{ns}}$ & 0.179 & $0.213^{n s}$ \\
\hline & Rec Posterior & - & - & 0.038 & $0.791^{n s}$ & 0.102 & $0.48^{n s}$ \\
\hline & CAL Posterior & - & - & -0.091 & $0.531^{\mathrm{ns}}$ & 0.113 & $0.434^{\mathrm{ns}}$ \\
\hline & BL Anterior & - & - & -0.049 & $0.736^{\mathrm{ns}}$ & -0.028 & $0.85^{\mathrm{ns}}$ \\
\hline & BL Posterior & - & - & 0.122 & $0.399^{n s}$ & -0.175 & $0.224^{\mathrm{ns}}$ \\
\hline \multirow[t]{11}{*}{ Time taken } & $\mathrm{PI}$ & - & - & -0.272 & $0.056^{\mathrm{ns}}$ & -0.202 & $0.159^{\mathrm{ns}}$ \\
\hline & $\mathrm{GI}$ & - & - & -0.381 & $0.006^{\star *}$ & -0.146 & $0.312^{n s}$ \\
\hline & BOP & - & - & 0.06 & $0.681^{\mathrm{ns}}$ & -0.113 & $0.434^{\mathrm{ns}}$ \\
\hline & PPD Anterior & - & - & 0.16 & $0.266^{\mathrm{ns}}$ & 0.08 & $0.579^{n s}$ \\
\hline & Rec Anterior & - & - & 0.046 & $0.75^{n s}$ & 0.087 & $0.548^{n s}$ \\
\hline & CAL Anterior & - & - & 0.036 & $0.806^{n s}$ & 0.014 & $0.922^{n s}$ \\
\hline & PPD Posterior & - & - & 0.271 & $0.057^{\mathrm{ns}}$ & -0.126 & $0.384^{n s}$ \\
\hline & Rec Posterior & - & - & -0.029 & $0.84^{n s}$ & -0.045 & $0.758^{n s}$ \\
\hline & CAL Posterior & - & - & 0.053 & $0.716^{n s}$ & 0.006 & $0.967^{n s}$ \\
\hline & BL Anterior & - & - & 0.156 & $0.278^{n s}$ & -0.185 & $0.197^{n s}$ \\
\hline & BL Posterior & - & - & 0.539 & $0.000^{* *}$ & -0.063 & $0.663^{n s}$ \\
\hline
\end{tabular}

PI: plaque index; GI: gingival index; BOP: bleeding on probing; PPD: probing pocket depth; Rec: recession; CAL: clinical attachment level; BL: bone loss; ns: not significant; ${ }^{\star} p<0.05$; Significant; ${ }^{\star \star} p<0.001$; highly significant

Since oral hygiene practices differ from person to person, significant differences were also observed between smokers and non-smokers, too, regarding oral hygiene practices [13]. These are close to our study finding in which most participants cleaned their teeth using toothbrush once a day (46.5 percent). We could not find any research comparing periodontal disease incidence among smokers using different types of oral hygiene aids. Research directed at oral health status as perceived by smokers and nonsmokers in England showed revealed more significant oral hygiene deficiency among smokers [14]. A similar pattern was seen in our 
group II sample, where most of them remembered that they had only been brushing for about one minute. Miswak users showed a successful two-minute oral hygiene method of brushing. The same subjects were performed in both classes regardless of the time required for brushing, up and down movement.

Multiple cross-sectional and longitudinal studies have widely identified the adverse effects of smoking on the periodontium. Increased pocket depth measurements, attachment loss, and alveolar bone loss are more prevalent in smokers than non-smokers [15]. The number of cigarettes used per day was in group III (11.52 \pm 6.37$)$, and in group II $(9.90 \pm 2.57)$ was lowest. Similarly, group II reported the longest time of smoking cigarettes, while it was shortest for group III ( $p=$ 0.248).

It is probably not the number of cigarettes, but the harmful chemicals it releases because smoking even a couple of cigarettes a day increases the risk of ischemic disease and lung cancer to a larger extend [16]. Hence, even light smokers have the possibility of encountering health issues. Another study showed median life expectancy was shorter by almost ten years for lifelong non-daily smokers than never smokers [17].

The lower $\mathrm{Pl}$ and $\mathrm{GI}$ (indicative of oral hygiene status) seen in miswak users than users of the toothbrush indicate the protective function of miswak exerts. Different studies indicate substantial improvement in plaque score and gingival health using Miswak as an alternative to tooth brushing [18]. The practice of brushing twice daily with miswak has been found to produce a notable reduction in gingivitis in the buccal aspect when compared with tooth brushing. However, there was only a minor improvement in the lingual aspect [18]. Not only is there improvement in the oral hygiene status, but also a reduction in the levels of subgingival microbiota such as Aggregatibacter actinomycetemcomitans and Porphyromonas gingivalis has been found [19]. This could be due to the release of benzyl isothiocyanate (BITC) [19].

A few randomized trials show that users of miswak demonstrate an improved mean gingival score and a substantial decrease in the bleeding index (BI) following the use of $S$. persica extract chewing gum [20]. This change may be due to the properties of antimicrobial in S. persica [21]. The miswak users had less recession in terms of gingival recession than other participants. Similar findings were found in an earlier study while other mentions miswak had scrubbed too much of the tooth surfaces and induced gingival recession [22].

A favourable oral hygiene index score but higher gingival recession scores in miswak (S. persica) may influence periodontal health [22]. The prevalence and magnitude of gingival recession in miswak and toothbrush users are very similar. However, it has been attributed as a reason for the increased occlusal tooth wear in Saudi Arabia's young adults, along with other factors such as bruxism, pen, and nail-biting habits and high consumption of fruit juices [23].

\section{Strengths and limitations of this study}

Though some previous studies have compared smokers and non-smokers, this is the first research documenting the periodontal status of smokers who are exclusive miswak users for oral hygiene maintenance. Furthermore, there are no reports so far evaluating various oral hygiene practices among smokers from most parts of this country. Tooth loss is often considered a direct result of smoking, but this criterion could not be included in the assessment as most participants could not remember the cause of extraction correctly (periodontitis or caries) [2]. In this area, caries are also found to be the leading cause of extraction [23]. While Miswak showed improvement in some periodontal parameters, there are few disadvantages associated. Although similar in function, miswak, and toothbrushes have designs that vary. The bristles of the miswak are located along the long axis of its handle. This could make lingual and interdental aspects inaccessible while toothbrush permits easy access even in the posterior teeth distal tooth surfaces.

The World Health Organization has advocated the use of these herbal tools for oral hygiene and is in line with the principles of the Primary Health Care Approach. Miswak is recommended as an alternative to the toothbrush for optimum oral health and hygiene, but attaining its optimum effects depends on its routine use with proper and efficient techniques. Though miswak has oral health benefits in smokers, its use should be further studied in conjunction with daily toothbrushing and oral hygiene treatment. Due to its antimicrobial, antioxidant, anticonvulsant, sedative, analgesic and anti-inflammatory activity, miswak with an alternative nicotine source is also recommended for patients on a smoking cessation program [24].

Trop J Pharm Res, October 2020; 19(10): 2210 


\section{CONCLUSION}

Within the limitations of this study, it can be noted that the incidence of periodontal damage among adult current smokers is lower in exclusive miswak users than in exclusive toothbrush users. Besides, because of its excellent mechanical plaque-removing efficiency and a wide variety of therapeutic properties, miswak may be considered an effective oral hygiene tool for smokers.

\section{DECLARATIONS}

\section{Acknowledgement}

This study was supported by Research Grant from the Maxillofacial Centre for Research, College of Dentistry, King Khalid University, Abha, Saudi Arabia (Research grant no. MRMC 01-019-009). The authors are thankful to the Maxillofacial Centre for Research and Dean, College of Dentistry, King Khalid University for all the support in the conduct of this study. We also thank Dr Baiju KV Ph.D, Assistant Professor, Department of Statistics, Kerala, India for the advice and suggestions.

\section{Conflict of interest}

No conflict of interest is associated with this work.

\section{Contribution of authors}

We declare that this work was done by the authors named in this article and all liabilities pertaining to claims relating to the content of this article will be borne by the authors.

\section{Open Access}

This is an Open Access article that uses a funding model which does not charge readers or their institutions for access and distributed under the terms of the Creative Commons Attribution License (http://creativecommons.org/licenses/by/ 4.0) and the Budapest Open Access Initiative (http://www.budapestopenaccessinitiative.org/rea d), which permit unrestricted use, distribution, and reproduction in any medium, provided the original work is properly credited.

\section{REFERENCES}

1. Bergstrom J, Eliasson S, Dock J. A 10-year prospective study of tobacco smoking and periodontal health. $J$ Periodontol 2000; 71(8):1338-1347.
2. Bolin A, Eklund G, Frithiof L, Lavstedt S. The effect of changed smoking habits on marginal alveolar bone loss. A longitudinal study. Swed Dent J 1993; 17(5):211-216.

3. Haque MM, Alsareii SA. A review of the therapeutic effects of using miswak (Salvadora Persica) on oral health. Saudi Med J 2015; 36(5):530-543.

4. Ezoddini-Ardakani F. Efficacy of Miswak (salvadora persica) in preventing dental caries. Health 2010; 2(5): 499-503.

5. Almas K, Al-Lafi TR. The natural toothbrush. World Health Forum 1995; 16(2):206-210.

6. Almas K. Miswak (chewing stick) and its role in oral health. Postgraduate Dent 1993; 3: 214-218.

7. Gazi MI, Davies TJ, al-Bagieh N, Cox SW, The immediate- and medium-term effects of Meswak on the composition of mixed saliva. J Clin Periodontol 1992; 19(2):113-117.

8. Guile E, Al-Shammery A, El-Backly M. Oral health survey of Saudi Arabia: oral health knowledge, attitudes, and practice among adults. J Dent Res 1996; 75: 1276 1280.

9. Darout IA, Albandar JM. Skaug N. Periodontal status of adult Sudanese habitual users of miswak chewing sticks or toothbrushes. Acta Odontol Scand 2000; 58(1):2530.

10. Caton JG, Armitage G, Berglundh T, Chapple IL, Jepsen S, Kornman KS, Mealey BL, Papapanou PN, Sanz M, Tonetti MS. A new classification scheme for periodontal and peri-implant diseases and conditions-Introduction and key changes from the 1999 classification. J Periodontol 2018; 89(Suppl 1): S1-S8.

11. Anil S. Study of the patterns of periodontal destruction in smokers with chronic periodontitis. Indian J Dent Res 2008; 19(2):124-128.

12. Petrovic M, Kesic L, Obradovic R, Savic Z, Mihailovic $D$, Obradovic I, Avdic-Saracevic M, Janjic-Trickovic O, Janjic M. Comparative analysis of smoking influence on periodontal tissue in subjects with periodontal disease. Materia sociomed 2013; 25(3):196 - 198.

13. Al-Qurashi H, Al-Farea M, Al-Qurai T, Al-Kadi M, AlBassam B, Nazir MA. Comparison of oral hygiene practices and oral health problems among smoker and non-smoker male adolescents in the Eastern Province of Saudi Arabia. Saudi J Dent Res 2016; 7:106-111.

14. Csikar J, Kang J, Wyborn C, Dyer TA, Marshman Z, Godson J. The self-reported oral health status and dental attendance of smokers and non-smokers in England. PLoS One 2016; 11(2): e0148700.

15. Cengiz Mi, Zengin B, liçen M, Köktürk F. Prevalence of periodontal disease among mine workers of Zonguldak, Kozlu District, Turkey: a cross-sectional study. BMC Public Health 2018; 18(1):361-367.

16. Bjartveit $K$, Tverdal A. Health consequences of smoking 1-4 cigarettes per day. Tob Control 2005; 14(5):315320.

17. Inoue-Choi M, McNeel TS, Hartge P, Caporaso NE, Graubard BI, Freedman ND. Non-Daily Cigarette

Trop J Pharm Res, October 2020; 19(10): 2211 
Smokers: Mortality Risks in the US. Am J Prev Med 2019; 56(1):27-37.

18. Patel PV, Shruthi S, Kumar S. Clinical effect of miswak as an adjunct to tooth brushing on gingivitis. $J$ Indian Soc Periodontol 2012; 16(1):84-88.

19. Al-Otaibi M, Al-Harthy M, Soder B, Gustafsson A, Angmar-Mansson B. Comparative effect of chewing sticks and toothbrushing on plaque removal and gingival health. Oral Health Prev Dent 2003; 1(4):301-307.

20. Saha S, Mohammad S, Saha S, Samadi F. Efficiency of traditional chewing stick (miswak) as an oral hygiene aid among Muslim school children in Lucknow: A crosssectional study. J Oral Biol Craniofac Res 2012; 2(3):176-180.
21. Hardie J, Ahmed K. The miswak as an aid in oral hygiene. J Philipp Dent Assoc 1995; 47(1):33-38.

22. Qureshi AA, Qureshi AA, Dohipoide A, Jamadar NN. Effects of Miswak-Salvadora Persica on Oral Health. Al Ameen J Med Sci 2016; 9(4):215-218.

23. Gossadi YI, Nahari HH, Kinani HM, Abdelwahab SI, Boreak NM, Abidi NH, Al Shawkani HA, Al Moaleem MM. Reasons for permanent teeth extraction in Jizan region of Saudi Arabia. J Dent Med Sci 2015; 14:86-89.

24. Nolan MB, Warner DO. Perioperative tobacco use treatments: putting them into practice. BMJ 2017: 358: j3340. 